Miguel Martín-Romero David Clavero-Martínez Antonia María CastilloNavarro Elisa Garcia-Vázquez

\section{Neisseria meningitidis bacteraemia and SARS-CoV-2 infection: a coinfection that reminds previous epidemic outbreaks}

Department of Internal Medicine, Hospital Clínico Universitario Virgen de la Arrixaca, Murcia, Spain.

Article history

Received: 19 October 2021; Revision Requested: 26 November 2021; Revision Received: 22 December 2021; Accepted: 15 January 2022; Published: 4 March 2022

\section{Sir,}

We hereby report the clinical case of an 89-year-old woman who was institutionalized in a nursing home. In March 2020, she was referred to the Emergency Care due to high fever $\left(39^{\circ} \mathrm{C}\right)$, overall health impairment, nausea and dry cough. On physical examination, fever $\left(38^{\circ} \mathrm{C}\right)$ and abnormal pulmonary auscultation (right lower lung inspiratory crackles) were found. The heart rate 90 beats per minute, the blood pressure 159/70 $\mathrm{mmHG}$, the respiratory rate 18 breaths per minute and the oxygen saturation $94 \%$ while the patient was breathing ambient air. There were no rashes or petechiae. No signs of neurological impairment were observed. Chest-X-ray showed right basal infiltrate consistent with pneumonia. The white-cell count was $27.940 / \mathrm{mm}^{3}$ (89\% polymorphonuclear cells), the haematocrit was 35\% and the platelet count was $159.000 / \mathrm{mm}^{3}$. A comprehensive metabolic panel was notable for a procalcitonin level of 7,47 ng/ml and the C-reactive protein level was $8,48 \mathrm{mg} / \mathrm{dl}$. Blood cultures were collected and nasopharyngeal smear samples for seasonal flu and SARS-CoV-2 RT-PCR were negative. The patient was hospitalized and antibiotic treatment was initiated. Blood cultures yield positive for penicillin-susceptible Neisseria meningitidis (MIC = $0,016 \mathrm{mg} / \mathrm{L}$ ) and the patient received a ceftriaxone course.

Chest CT scan was requested and confirmed lobar pneumonia in the lower right lobe (Figure 1). After 5 days of hospital stay, the fever persistence and the confirmation of a SARSCoV-2 outbreak in the nursing home lead to a second RT-PCR, which turned out with a positive result. With a radiographic pattern suggestive of bacterial pneumonia, elevation of procalcitonin level, and in absence of neurological symptoms, the infection was interpreted as $N$. meningitidis pneumonia in the context of SARS-CoV-2 infection, although sputum samples confirming its etiology were not available. She was transferred

Correspondence:

Miguel Martin Romero

Department of Internal Medicine, Hospital Clínico Universitario Virgen de la Arrixaca, Murcia Spain.

E-mail: miguelmr1990@gmail.com to the respiratory isolation unit and symptomatic treatment for SARS-CoV-2 infection was initiated. No respiratory impairment was observed during hospitalization and fever disappeared after four more days. Patient was finally discharged after full recovery, normalization of analytical parameters and negative SARS-CoV-2 RT-PCR.

N. meningitidis is a Gram-negative aerobic diplococcus carried asymptomatically in up to $20 \%$ of the population [1]. Humans are the only natural reservoir of $N$. meningitidis, and the nasopharynx is the site from which they are transmitted to others by aerosol or secretions. Meningococci overcome host defenses and attach to the microvillous surface of nonciliated columnar mucosal cells of the nasopharynx, where they multiply and colonize the host [2]. Invasive disease is only developed in a minority of cases, and it represents a rare but severe event. Meningococcal meningitis is by far the most common clinical presentation, followed by bacteraemia and pneumonia. The latter was firstly described in 1918 during the wrongly called "Spanish flu pandemic" [3], during which an unusually high incidence of this complication was reported [4]. Person to person spread takes place by respiratory droplet infection. It is facilitated by some factors, like active or passive exposure to tobacco smoke, as well as by concurrent viral infections of the upper respiratory tract, because those situations enhance the formation and spread of droplets, and they also reduce the functional and mechanical integrity of the respiratory mucosa as a barrier to invasion. Viruses may also induce immune dysregulation, which increases susceptibility to bacterial infections [2]. Thus, prior studies have noted a higher incidence of meningococcal disease during viral epidemic outbreaks, especially related to Influenza virus [5]. These findings have been reported both at small scale (within families or classmates), but also at larger scale, identifying more virulent meningococcal infection rates and higher than usual after pandemic outbreaks (i.e. in the United Kingdom in 1957, 1976 and 1989, or in France between 1985 and 1990) $[6,7]$. It has been suggested that a concomitant viral infection could foster N. meningitidis invasion of local bloodstream caus- 


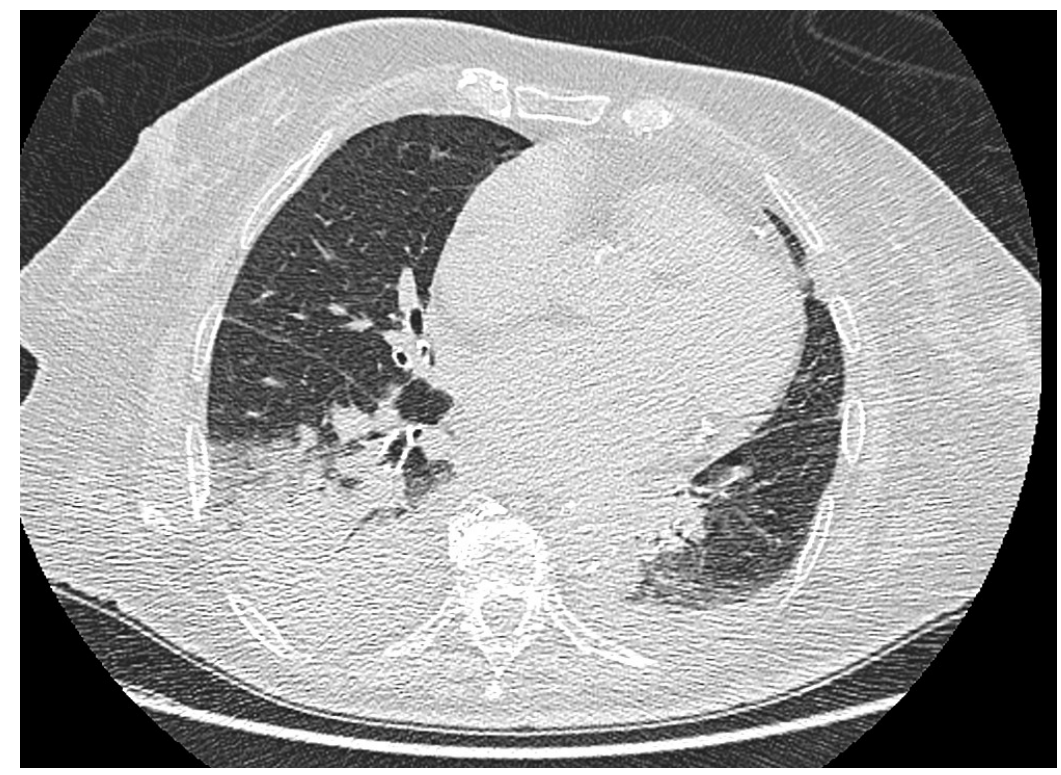

\begin{tabular}{l|l} 
Figure 1 & Chest CT scan showing pulmonary consolidation with air
\end{tabular} bronchogram consistent with lobar pneumonia in the lower right lobe.

ing bacteraemia, and then dissemination of the pathogen to other tissues such as the lungs. Other possible explanations for meningococcal pneumonia include inhalation of contaminated respiratory droplets from infected patients, or microaspirations from colonized pharynx to respiratory airways [2]. In the case we present, the radiological features of the lung infiltrate were not the typical of COVID-19 pneumonia and the patient did not develop respiratory impairment, therefor it can be suspected that the pneumonia had a bacterial aetiology rather than a viral one.

In conclusion, although morbimortality of COVID-19 is closely and mainly related to inflammatory and microthrombotic lung complications, we highlight its possible association with pulmonary bacterial coinfections, both by common pathogens [8] but also by other less frequent pathogens such as $N$. meningitidis. A greater focus on the implications of this association could foster an early detection and appropriate treatment of patients who present with these complications.

\section{FUNDING}

None to declare.

\section{CONFLICTS OF INTEREST}

The authors declare no conflicts of interest.

\section{REFERENCES}

1. Caugant DA, Tzanakaki G, Kriz P. Lessons from meningococcal carriage studies. FEMS Microbiol Rev. 2007;31(1):52-63. DOI: $10.1111 /$ j.1574-6976.2006.00052.x
2. Rosenstein NE, Perkins BA, Stephens DS, Popovic T, Hughes JM. Meningococcal disease. N Engl J Med. 2001;344(18):1378-88. DOI: 10.1056/NEJM200105033441807

3. Fletcher W. Meningococcus bronchopneumonia in influenza. Lancet. 1919;16:104-105.

4. Holm ML, Davison WC. The occurrence of post-influenzal pneumonia in which the diplococcus intracellularis meningitidis was isolated. From observations at Camp Coetquidon. A. E. F., France. Bull John Hopkins Hosp. 1919;30:324-9.

5 Jacobs JH, Viboud C, Tchetgen ET, Schwartz J, Steiner C, Simonsen $L$ et al. The association of meningococcal disease with influenza in the United States, 1989-2009. PLoS One. 2014;9(9):e107486. DOI: 10.1371/journal.pone.0107486

6. Brundage JF. Interactions between influenza and bacterial respiratory pathogens: implications for pandemic preparedness. Lancet Infect Dis. 2006;6(5):303-312. DOI: 10.1016/S14733099(06)70466-2

7. Hubert B, Watier L, Garnerin P, Richardson S. Meningococcal disease and influenza-like syndrome: a new approach to an old question. J Infect Dis. 1992;166:542-45. DOI: 10.1093/infdis/166.3.542

8. Moral Escudero E, Hernández Torres A, Roura Piloto AE, Albendín Iglesias H, Peláez Ballesta A, García Vázquez E. Neumonía neumocócica en pacientes con infección por SARS-CoV-2: serie de 17 casos en la Región de Murcia. Rev Esp Quimioter. 2021; 34(5):491495. DOI: $10.37201 / \mathrm{req} / 151.2020$ 